\title{
SOBREVIVÊNCIA E CRESCIMENTO INICIAL DE ESPÉCIES ARBÓREAS NATIVAS IMPLANTADAS EM PASTAGEM DEGRADADA
}

\author{
Natália Hilgert de Souza Carnevali ${ }^{1 *}$, Etenaldo Felipe Santiago ${ }^{1}$, Danilo de Menezes Daloso ${ }^{2}$, \\ Thiago de Oliveira Carnevali ${ }^{3}$, Maiby Teodoro de Oliveira $^{3}$ \\ ${ }^{1}$ Universidade Estadual de Mato Grosso do Sul, Centro Integrado de Análise e Monitoramento Ambiental, Dourados, Mato Grosso do Sul, \\ Brasil - natalia_hilgert@hotmail.com*, felipe@uems.br, thiagocarnevali@live.com \\ ${ }^{2}$ Universidade Federal do Ceará, Centro de Ciências, Departamento de Bioquímica e Biologia Molecular, Campus do Pici, Fortaleza, Ceará, \\ Brasil - danilo_biologo@yahoo.com.br \\ ${ }^{3}$ Universidade Federal de Santa Catariana, Programa de Pós-Graduação Recursos Genéticos Vegetais, Florianópolis, Santa Catarina, Brasil - \\ maibyoli@hotmail.com
}

Recebido para a publicação: 28/08/2015 - Aceito para a publicação: 06/04/2016

\begin{abstract}
Resumo
O presente trabalho teve por objetivo analisar e comparar o crescimento inicial de espécies nativas de diferentes grupos sucessionais implantadas em área de pastagem degradada e monitorar a evolução da biodiversidade local por meio da regeneração natural. O estudo foi desenvolvido no município de Jateí, estado de Mato Grosso do Sul, Brasil. Analisou-se, durante um ano, altura de plantas, diâmetro do colo, projeção da copa e taxa de sobrevivência, em três subáreas de $400 \mathrm{~m}^{2}$ : (I) declividade de $10 \%$, (II) declividade de $14 \%$ e (III) barranco erodido. Propôs-se um delineamento inteiramente casualizado com os representantes de cada espécie constituindo o número de repetições. As espécies pioneiras e secundárias iniciais apresentaram maior crescimento e adaptação ao ambiente, destacando-se Maclura tinctoria, Myracrodruon urundeuva, Cedrela odorata, Peltophorum dubium e Anadenanthera colubrina, as quais podem ser indicadas para restauração florestal de áreas degradadas.

Palavras-chave: Restauração florestal; área de preservação permanente; sucessão ecológica.
\end{abstract}

\begin{abstract}
Survival and initial growth of native tree species implanted in degraded pastures. This study aimed to monitor the initial growth and survival of Brazilian native species from different successional groups grown in Permanent Preservation Areas degraded by pasture activity. The study was conducted in Jateí city, State of Mato Grosso do Sul, Brazil. Plants were analyzed for one year, the plant height, stem diameter, crown projection and survival in three sub-areas. It was proposed a completely randomized design with individuals of each species representing the number of repetitions. The pioneer species and early secondary showed higher growth and adaptation to the environment, especially Maclura tinctoria, Myracrodruon urundeuva, Cedrela odorata, Peltophorum dubium and Anadenanthera colubrina which may be indicated for recovery plant of degraded pasture.

Keywords: Forest restoration; permanent preservation area; ecological succession.
\end{abstract}

\section{INTRODUÇÃO}

A degradação ambiental é normalmente o resultado de práticas não sustentáveis no uso dos recursos naturais. No Mato Grosso do Sul, em especial nas áreas de pastagens, são comuns regiões caracterizadas pelo histórico de manejo inadequado com consequente prejuízo aos atributos físico-químicos dos solos além da drástica redução da biodiversidade. Em linhas gerais, este não é um processo simples de ser revertido, pois ecossistemas degradados podem perder seus meios naturais de regeneração biótica ou essa tornar-se muito lenta (SHONO et al., 2007; RODRIGUES et al., 2010). Nesse contexto, intervenções no âmbito da reposição de cobertura vegetal nativa são fundamentais para estabilizar e reverter processos de degradação em ecossistemas não mais capazes de repor perdas de matéria orgânica, nutrientes e fontes de propágulos.

Vários fatores podem interferir num processo de restauração, sendo extremamente importante conhecer o ecossistema envolvido, considerando a relação estrutura-função, além da dinâmica do mesmo, interrelacionando a troca de matéria e energia com ecossistemas adjacentes (EHRENFELD; TOTH, 1997). A escolha das espécies a serem implantadas na área deve obedecer a florística nativa circundante para tornar o ambiente mais próximo do original, recuperando não só a sua estrutura, mas também sua funcionalidade (FERREIRA et al., 2007), sendo esse o princípio da restauração ecológica. 
As espécies vegetais arbóreas têm ritmos de crescimento e necessidades ecológicas diferentes nos diversos estádios de desenvolvimento. Devido a isso, em programas de restauração florestal, atenção especial deve ser dada ao comportamento das espécies nativas frente às condições ambientais, garantindo assim baixa mortalidade e bom desempenho no crescimento (GÜNTER et al., 2009). Nesse sentido, a classificação das espécies em grupos ecológicos é essencial para a compreensão da sucessão ecológica, já que a classificação da autoecologia das espécies auxilia na compreensão da dinâmica florestal e na adoção de práticas adequadas de manejo e reposição de cobertura florestal.

A análise de crescimento e desenvolvimento de espécies florestais nativas plantadas em áreas degradadas pode contribuir para viabilizar espécies com maior potencial de crescimento e desenvolvimento frente às perturbações ambientais encontradas em ambientes degradados. Assim, o objetivo deste trabalho foi analisar e comparar o crescimento inicial de espécies nativas de diferentes grupos sucessionais implantadas em área de pastagem degradada, indicando as espécies com maior potencial de restauração florestal.

\section{MATERIAIS E MÉTODOS}

O estudo foi desenvolvido em área de pastagem degradada no município de Jateí, MS. O solo da área é do tipo Podzólico Vermelho Amarelo, de baixa fertilidade natural, com as seguintes características físicas e químicas, segundo metodologia proposta por Silva et al. (2009): silte $249 \mathrm{~g} \mathrm{~kg}^{-1}$; argila $109 \mathrm{~g} \mathrm{~kg}^{-1}$; areia fina $468 \mathrm{~g} \mathrm{~kg}^{-1}$; areia grossa $145 \mathrm{~g} \mathrm{~kg}^{-1}$; matéria orgânica $15 \mathrm{~g} \mathrm{~kg}^{-1} ; \mathrm{pH} 4,5 ; \mathrm{P}=3,0 \mathrm{mg} \mathrm{dm}{ }^{-3} ; \mathrm{K}^{+}=1 \mathrm{mmol}_{\mathrm{c}} \mathrm{dm}^{-3} ; \mathrm{Ca}^{2+}$ $=4,0 \mathrm{mmol}_{\mathrm{c}} \mathrm{dm}^{-3} ; \mathrm{Mg}^{2+}=3,0 \mathrm{mmol}_{\mathrm{c}} \mathrm{dm}^{-3} ; \mathrm{Al}^{3+}=14,1 \mathrm{mmol}_{\mathrm{c}} \mathrm{dm}^{-3} ; \mathrm{H}+\mathrm{Al}=76,0 \mathrm{mmol}_{\mathrm{c}} \mathrm{dm}^{-3} ; \mathrm{SB}=8,0 \mathrm{mmol}_{\mathrm{c}}$ $\mathrm{dm}^{-3} ; \mathrm{T}=84 \mathrm{mmol}_{\mathrm{c}} \mathrm{dm}^{-3}, \mathrm{~V} \%=9,52$.

A área de estudo $\left(54^{\circ} 18^{\prime} 15,01^{\prime \prime}\right.$ W e $\left.22^{\circ} 28^{\prime} 40,40^{\prime \prime} \mathrm{S}\right)$ está associada ao entorno de uma Área de Preservação Permanente (APP), que abriga nascentes de córregos que formam a sub-bacia do Rio Ivinhema, afluente do Rio Paraná. O clima da região, segundo a classificação de Köppen é do tipo AW, apresentando estação chuvosa no verão e seca no inverno. As temperaturas máximas e mínimas, umidade relativa do ar e precipitação na época de desenvolvimento do experimento constam na figura 1.

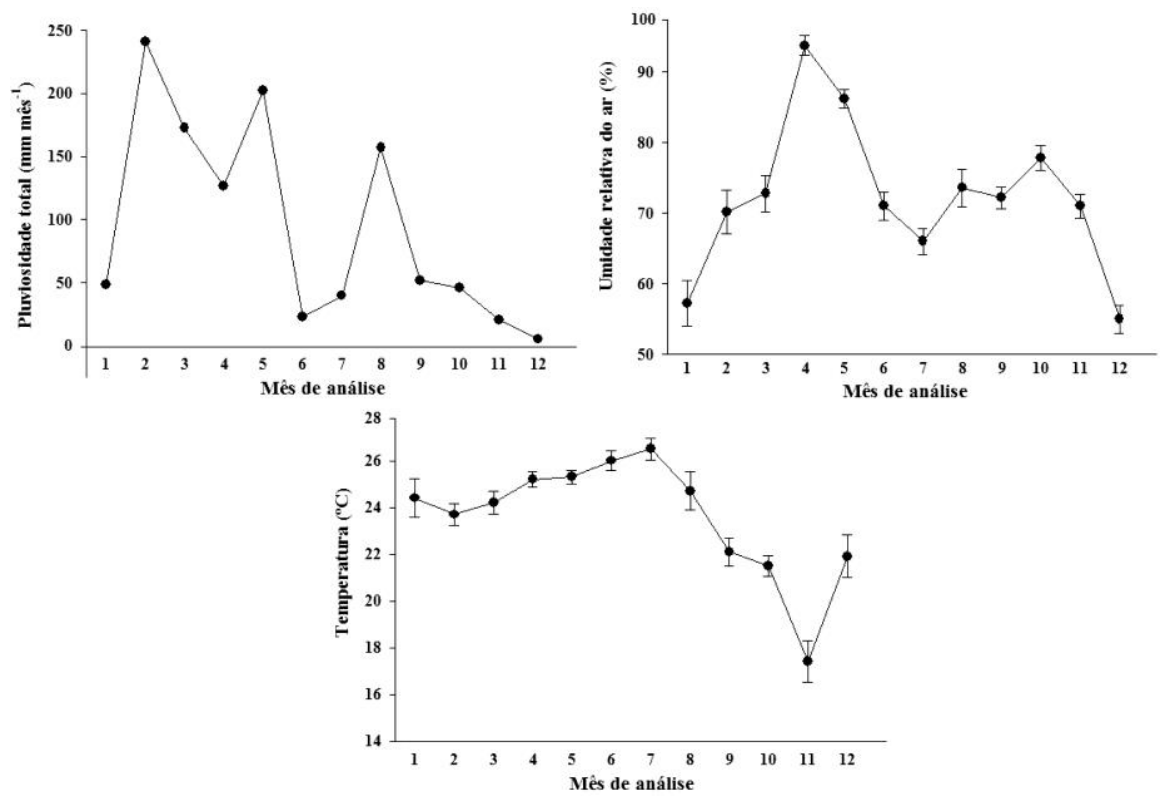

Figura 1. Variações mensais em pluviosidade total ( $\mathrm{mm} / \mathrm{mês})$, umidade relativa do ar $(\%)$ e temperatura média $\left({ }^{\circ} \mathrm{C}\right.$ ), no período de setembro/2004 (mês 1) a agosto/2005 (mês 12). Barras em torno dos valores médios demonstram o erro padrão.

Figure 1. Monthly variations in total rainfall (mm / month), relative humidity $(\%)$ and average temperature $\left({ }^{\circ} \mathrm{C}\right)$, from September/2004 (month 1) to August/2005 (month 12). Bars around the mean values show the standard error.

As mudas foram produzidas no Sítio Escola de Jateí, MS a partir de sementes coletadas na APP. Dependendo do tamanho das sementes, a semeadura ocorreu em bandejas de poliestireno, tubetes ou sacos plásticos, contendo substrato agrícola e esterco bovino curado na proporção 3:1 enriquecido com 200 g de NPK 
4-14-8 e mantidas em viveiro sob cobertura sombrite 50\% e irrigadas diariamente. Após um período de 30-50 dias da germinação, as mudas foram supridas com adubação foliar de macro e micronutrientes de formulado comercial, a cada sete dias. Por volta de dois a três meses da emergência, as plantas foram submetidas a condições de rustificação, tais como redução gradativa da irrigação e adubação, e para as espécies pioneiras manutenção a sol pleno para seleção dos indivíduos mais resistentes. As mudas foram plantadas com idade variando de três a quatro meses. As espécies selecionadas encontram-se na tabela 1.

Tabela 1. Espécies utilizadas no plantio experimental em pastagem degradada em Jateí, MS.

Table 1. Species used in the experimental planting in degraded pastures in Jateí, MS.

\begin{tabular}{|c|c|c|c|}
\hline Família & Nome Científico & Nome Popular & Grupo Sucessional \\
\hline Anacardiaceae & Myracrodruon urundeuva Allemão & Aroeira & $\mathrm{P}$ \\
\hline Apocynaceae & Aspidosperma sp. Mart. & Guatambu & $\mathrm{C}$ \\
\hline Bignoniaceae & $\begin{array}{l}\text { Handroanthus vellosoi } \\
\text { (Toledo) Mattos }\end{array}$ & Ipê & St \\
\hline Malvaceae & Pachira glabra Pasq. & Castanha-do-maranhão & St \\
\hline Boraginaceae & Cordia trichotoma (Vell.) Arráb. ex Steud. & Louro-pardo & St \\
\hline Boraginaceae & $\begin{array}{l}\text { Cordia brasiliensis } \\
\text { (I.M.Johnst.) Gottschling \& J.S.Mill. }\end{array}$ & Louro & St \\
\hline Fabaceae-Caesalpinioideae & Pterogyne nitens Tul. & Amendoim & $P$ \\
\hline Fabaceae-Caesalpinioideae & $\begin{array}{l}\text { Tachigali aurea } \\
\text { Tul. }\end{array}$ & Sucupira & $\mathrm{Si}$ \\
\hline Fabaceae-Caesalpinioideae & Peltophorum dubium (Spreng.) Taub. & Canafístula & $P$ \\
\hline Fabaceae-Mimosoideae & $\begin{array}{l}\text { Senegalia polyphylla } \\
\text { (DC.) Britton \& Rose }\end{array}$ & Monjoleiro & $P$ \\
\hline Fabaceae-Mimosoideae & Albizia niopoides (Spruce ex Benth.) Burkart & Farinha-seca & $P$ \\
\hline Fabaceae-Mimosoideae & $\begin{array}{l}\text { Anadenanthera colubrina } \\
\text { var. cebil (Griseb.) Altschul }\end{array}$ & Angico-branco & $P$ \\
\hline Fabaceae-Mimosoideae & Inga vera subsp. affinis (DC.) T.D.Penn. & Ingá & $\mathrm{Si}$ \\
\hline Lecythidaceae & $\begin{array}{l}\text { Cariniana rubra } \\
\text { Gardner ex Miers }\end{array}$ & Jequitibá & $\mathrm{C}$ \\
\hline Malvaceae & $\begin{array}{l}\text { Luehea paniculata } \\
\text { Mart. \& Zucc. }\end{array}$ & Açoita-cavalo & $\mathrm{P}$ \\
\hline Meliaceae & Cedrela odorata $\mathrm{L}$ & Cedro & $\mathrm{Si}$ \\
\hline Moraceae & Ficus enormis Mart. ex Miq. & Figueira-branca & $\mathrm{P}$ \\
\hline Moraceae & Maclura tinctoria (L.) D.Don ex Steud. & Amoreira & $\mathrm{P}$ \\
\hline Myrtaceae & Eugenia uniflora $\mathrm{L}$. & Pitanga & St \\
\hline Polygonaceae & Triplaris americana $\mathrm{L}$ & Pau-formiga & $\mathrm{Si}$ \\
\hline Rubiaceae & Chimarrhis barbata (Ducke) Bremek. & Amarelinho & $\mathrm{Si}$ \\
\hline Rubiaceae & Genipa americana $\mathrm{L}$. & Jenipapo & $\mathrm{Si}$ \\
\hline Urticaceae & $\begin{array}{l}\text { Cecropia pachystachya } \\
\text { Trécul }\end{array}$ & Embaúba & $\mathrm{P}$ \\
\hline
\end{tabular}

Legenda: $\mathrm{P}$ - pioneiras, SI - secundárias iniciais, ST - secundárias tardias e C - climáxicas.

A área de plantio constituiu-se de três subáreas: (I) declividade de 10\%, (II) declividade de $14 \%$ e (III) barranco erodido, de $400 \mathrm{~m}^{2}$, sendo efetuado coveamento de $40 \times 40 \times 40 \mathrm{~cm}$, com adição de $20 \mathrm{~L}$ de esterco suíno curtido para receber as mudas nas parcelas. Por conta da declividade acentuada da subárea (III), as mudas foram mantidas em sacos biodegradáveis de $30 \mathrm{~kg}$ para a manutenção do substrato. Utilizou-se 36 plantas por área, das quais 28 eram pioneiras, 3 secundárias iniciais, 3 secundárias tardias e 2 climáxicas (Figura 2), seguindo um modelo heterogêneo em linha (BARBOSA, 2000), no espaçamento 4 x $4 \mathrm{~m}$.

As avaliações foram feitas com base na determinação da sobrevivência e crescimento por meio da medição da altura das plantas $(\mathrm{cm})$, diâmetro do colo $(\mathrm{mm})$ e projeção da copa $(\mathrm{cm})$, realizadas aos 60, 120, 180, 270 e 360 dias após o transplante (DAT), sendo a primeira avaliação em setembro/2004 e a última em agosto/2005. Devido ao alto índice de mortalidade das plantas, foram selecionadas para avaliação somente as espécies que apresentaram acima de $60 \%$ de sobrevivência até o final da coleta de dados, para tanto, foi aplicada a análise de Kaplan-Meier (KAPLAN; MEIER, 1958), sendo apontada a frequência de indivíduos vivos, com auxílio do programa Bioestat 5.0. Sendo assim, as espécies avaliadas na área I foram: Maclura tinctoria (L.) D.Don ex Steud. (amoreira-do-mato), Cedrela odorata L. (cedro), Chimarrhis barbata (Ducke) Bremek. (amarelinho), Genipa americana L. (jenipapo), Myracrodruon urundeuva Allemão (aroeira) e Peltophorum dubium (Spreng.) Taub. (canafístula); na área II: M. tinctoria, Anadenanthera colubrina (Vell.) Brenan (angico),

FLORESTA, Curitiba, PR, v. 46, n. 2, p. 277 - 286, abr. / jun. 2016.

Carnevali, N. H. de S. et al.

ISSN eletrônico 1982-4688

DOI: $10.5380 /$ rf.v46i2.42881 
Aspidosperma sp. Mart. (guatambu), Pachira glabra Pasq. (castanha-do-maranhão), Cariniana rubra Gardner ex Miers (jequitibá), Cordia trichotoma (Vell.) Arráb. ex Steud. (louro-pardo) e M. urundeuva; e na área III: Anadenanthera colubrina var. cebil (Griseb.) Altschul (angico), Inga vera subsp. affinis (DC.) T.D.Penn. (ingá), Luehea paniculata Mart. \& Zucc. (açoita-cavalo), M. urundeuva e P. dubium. As espécies provenientes de regeneração natural foram caracterizadas ao final do período experimental em todas as parcelas, sendo reconhecidas em nível de espécie, quando possível, através de comparação com a descrição de Lorenzi (2002).

\begin{tabular}{|c|c|c|c|c|c|c|c|c|}
\hline \multicolumn{9}{|c|}{ ÁREA 1} \\
\hline CANAFISTULA & CANo? & GUATAMBU & $\begin{array}{c}\text { FARINHA } \\
\text { SECA }\end{array}$ & PIANGA & AROEIRA & $\begin{array}{l}\text { ANGICO } \\
\text { BRANCO }\end{array}$ & III 1 ? & CANAFISTULA \\
\hline EMBAÚBA & AROEIRA & 18. & $\begin{array}{l}\text { AÇOITA } \\
\text { CAVALO }\end{array}$ & MONJOLEIRO & AMENDOIM & AMOREIRA & $\begin{array}{l}\text { FIGUEIRA } \\
\text { BRANCA }\end{array}$ & $\begin{array}{l}\text { ANGICO } \\
\text { BRANCO }\end{array}$ \\
\hline AMOREIRA & $\begin{array}{c}\text { FIGUEIRA } \\
\text { BRANCA }\end{array}$ & AMENDOIM & AMOREIRA & EMBAÚBA & GUATAMBU & rom & $\begin{array}{l}\text { AÇOITA } \\
\text { CAVALO }\end{array}$ & EMBAÚBA \\
\hline CANAFISTULA & IPE & $\begin{array}{l}\text { ANGICO } \\
\text { BRANCO }\end{array}$ & AROEIRA & Mal & $\begin{array}{l}\text { FARINHA } \\
\text { SECA }\end{array}$ & AROEIRA & IPE & CANAFISTULA \\
\hline \multicolumn{9}{|c|}{ ÁREA 2} \\
\hline CANAFISTULA & III 1 IIC- & GUATAMBU & $\begin{array}{l}\text { FARINHA } \\
\text { SECA }\end{array}$ & $\begin{array}{l}\text { CASTANHA } \\
\text { DO } \\
\text { HARANH OO }\end{array}$ & AROEIRA & $\begin{array}{l}\text { ANGICO } \\
\text { BRANCO }\end{array}$ & ctom: & CANAFISTULA \\
\hline EMBAÚBA & AROEIRA & mor. & $\begin{array}{l}\text { AÇOITA } \\
\text { CAVALO }\end{array}$ & MONJOLEIRO & AMENDOIM & AMOREIRA & $\begin{array}{l}\text { FIGUEIRA } \\
\text { BRANCA }\end{array}$ & $\begin{array}{l}\text { ANGICO } \\
\text { BRANCO }\end{array}$ \\
\hline AMOREIRA & $\begin{array}{c}\text { FIGUEIRA } \\
\text { BRANCA }\end{array}$ & AMENDOIM & AMOREIRA & EMBAÚBA & GUATAMBU & mormen & $\begin{array}{l}\text { AÇOITA } \\
\text { CAVALO }\end{array}$ & EMBAÚBA \\
\hline CANAFÍSTULA & $\begin{array}{l}\text { LULO } \\
\text { PARDO }\end{array}$ & $\begin{array}{l}\text { ANGICO } \\
\text { BRANCO }\end{array}$ & AROEIRA & StCUI। & $\begin{array}{l}\text { FARINHA } \\
\text { SECA }\end{array}$ & AROEIRA & $\begin{array}{l}\text { OOLO } \\
\text { PARDO }\end{array}$ & CANAFISTULA \\
\hline \multicolumn{9}{|c|}{ AREA 3} \\
\hline CANAFISTULA & Nil & GUATAMBU & FARINHA SECA & $\begin{array}{l}\text { TOURO } \\
\text { PARDO }\end{array}$ & AROEIRA & $\begin{array}{l}\text { ANGICO } \\
\text { BRANCO }\end{array}$ & 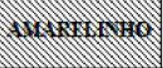 & CANAFISTULA \\
\hline EMBAÚBA & AROEIRA & mormon & $\begin{array}{l}\text { AÇOITA } \\
\text { CAVALO }\end{array}$ & MONJOLEIRO & AMENDOIM & AMOREIRA & $\begin{array}{l}\text { FIGUEIRA } \\
\text { BRANCA }\end{array}$ & $\begin{array}{l}\text { ANGICO } \\
\text { BRANCO }\end{array}$ \\
\hline AMOREIRA & $\begin{array}{l}\text { FIGUEIRA } \\
\text { BRANCA }\end{array}$ & AMENDOIM & AMOREIRA & EMBAÚBA & GUATAMBU & Then & $\begin{array}{l}\text { AÇOITA } \\
\text { CAVALO }\end{array}$ & EMBAÚBA \\
\hline CANAFISTULA & $\begin{array}{l}\text { CASTANHA } \\
\text { DO } \\
\text { NIARANHAO }\end{array}$ & $\begin{array}{l}\text { ANGICO } \\
\text { BRANCO }\end{array}$ & AROEIRA & (as) & $\begin{array}{l}\text { FARINHA } \\
\text { SECA }\end{array}$ & AROEIRA & $\begin{array}{l}\text { CASTANHA } \\
\text { DO } \\
\text { NARANHAO }\end{array}$ & CANAFISTULA \\
\hline
\end{tabular}

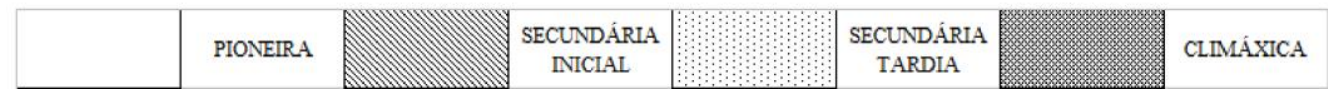

Figura 2. Croqui das espécies plantadas em cada área experimental, seguindo o modelo em linha, com $80 \%$ de pioneiras (BARBOSA, 2000).

Figure 2. Sketch of the species planted in each experimental area, following the model online, with $80 \%$ of pioneers (BARBOSA, 2000).

Propôs-se um delineamento inteiramente casualizado com os representantes de cada espécie constituindo o número de repetições. Os dados em porcentagem foram transformados para arco seno da raiz quadrada de $\mathrm{x}^{-100}$. As médias dos dados obtidos foram submetidas à análise de variância e quando se verificou significância pelo teste $\mathrm{F}$, foram ajustadas equações de regressão em função das épocas de avaliação e espécies, e teste Tukey a 5\% de significância, utilizando-se o aplicativo computacional SAEG 9.1 (RIBEIRO JÚNIOR; MELO, 2009).

\section{RESULTADOS}

Os resultados médios da porcentagem de sobrevivência das espécies (Figura 3) indicaram que houve comportamento distinto nas diferentes áreas. O maior percentual de sobrevivência foi obtido na área II, com declividade intermediária, e o menor percentual na área III, de maior declividade. Somente a aroeira esteve presente nas três áreas até o final do período de avaliação. No entanto, as espécies que apresentaram $100 \%$ de sobrevivência no mesmo período foram: amoreira e jenipapo, na área I; amoreira, castanha-do-maranhão, jequitibá e louro-pardo na área II; e na área III nenhuma espécie apresentou 100\% de sobrevivência. 

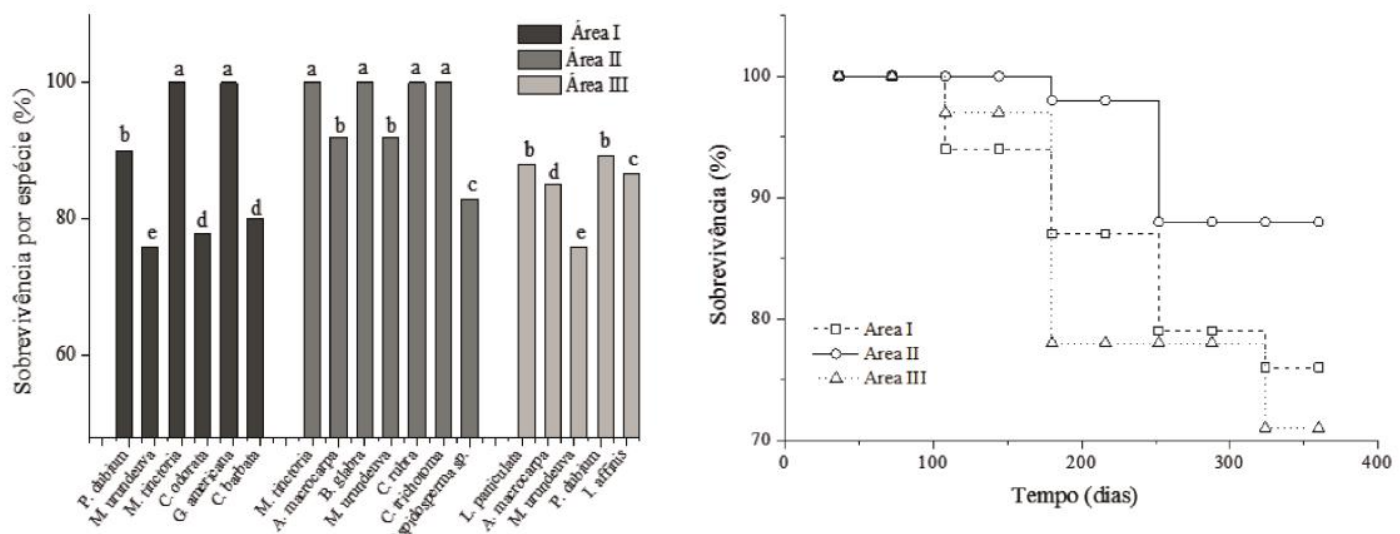

Figura 3. Porcentagem de sobrevivência das espécies inseridas nas diferentes áreas (I, II e III) e em função do tempo. Médias seguidas pela mesma letra, nas colunas, não diferem entre si pelo teste Tukey a 5\% de significância.

Figure 3. Percent survival of the species included in different areas (I, II and III) and as a function of time. Means followed by the same letter in the columns do not differ by Tukey test at 5\% significance.

A análise de variância indicou interação significativa para os dados de altura de plantas e diâmetro de colo nas áreas I, II e III (Figuras 4, 5 e 6, respectivamente) e projeção de copa na área II (Figura 5), das diferentes espécies em função do tempo de avaliação. $\mathrm{Na}$ área I, as espécies que apresentaram maiores valores de altura e diâmetro foram a canafístula $(79,78 \mathrm{~cm}$ e $20,88 \mathrm{~mm}$, respectivamente), o cedro $(58,74 \mathrm{~cm}$ e $16,49 \mathrm{~mm}$, respectivamente) e a amoreira-do-mato $(61,29 \mathrm{~cm}$ e $14,5 \mathrm{~mm}$, respectivamente). A canafístula foi a espécie que apresentou maior projeção de copa, de 40,92 cm (Tabela 2).
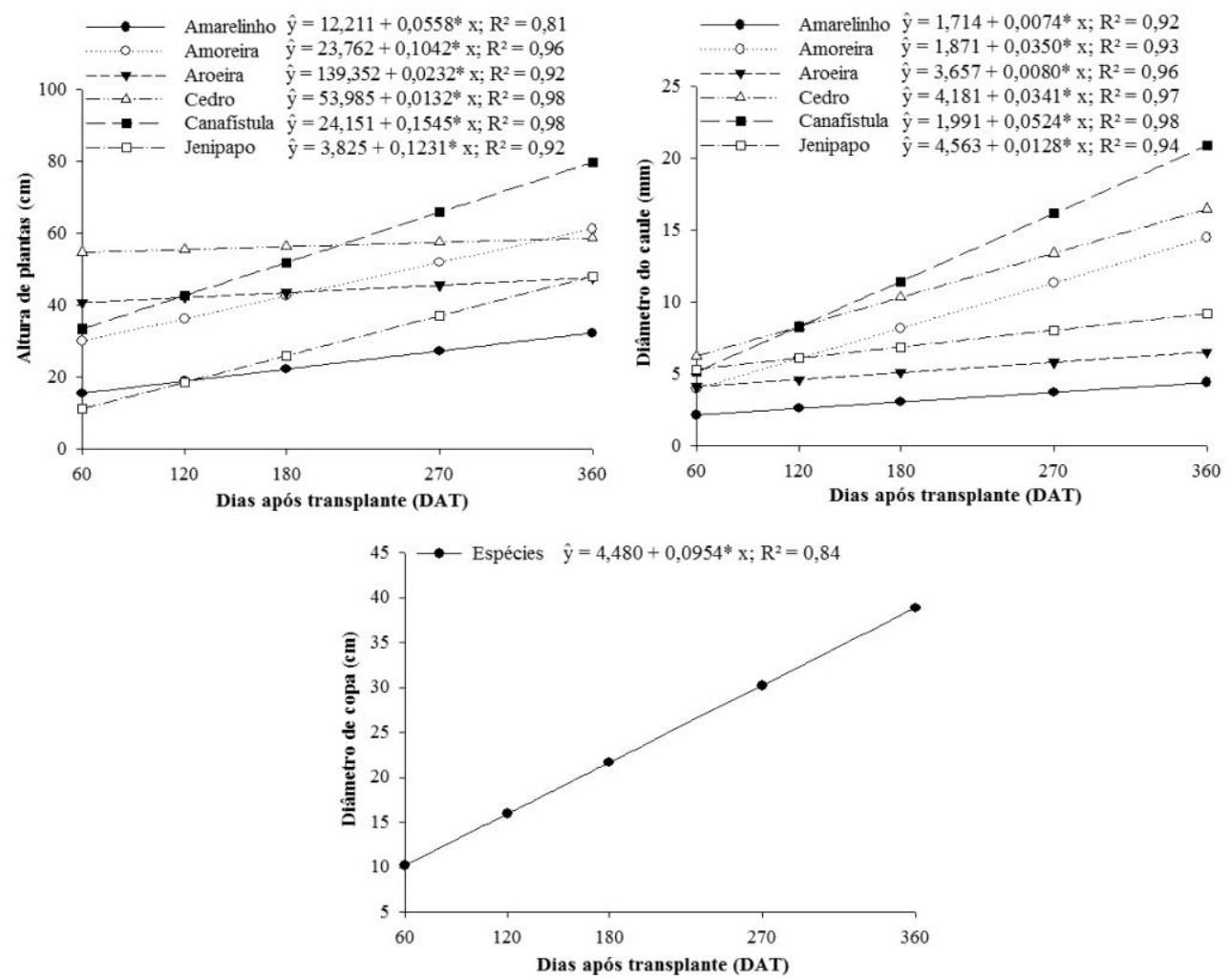

Figura 4. Altura, diâmetro do colo e projeção da copa das espécies inseridas na área I de acordo com as épocas de avaliação.

Figure 4. Height, stem diameter and canopy projection of the species included in the area I according to the evaluation periods. 
Tabela 2. Projeção da copa das espécies inseridas nas áreas I e III. As médias de época foram agrupadas. Table 2. Crown projection of species included in the areas I and III. The average time were grouped.

\begin{tabular}{lcc}
\hline \multirow{2}{*}{ Espécies } & \multicolumn{2}{c}{ Copa cm/planta } \\
\cline { 2 - 3 } & Área I & Área III \\
\hline Canafístula & $40,92 \mathrm{a}$ & $43,12 \mathrm{a}$ \\
Aroeira & $22,54 \mathrm{~b}$ & $28,68 \mathrm{ab}$ \\
Amoreira-do-mato & $22,23 \mathrm{~b}$ & - \\
Cedro & $19,65 \mathrm{~b}$ & - \\
Jenipapo & $17,65 \mathrm{bc}$ & - \\
Amarelinho & $10,32 \mathrm{c}$ & - \\
Angico & - & $33,41 \mathrm{ab}$ \\
Açoita-cavalo & - & $28,10 \mathrm{ab}$ \\
Ingá & - & $25,34 \mathrm{~b}$ \\
\hline C.V.(\%) & 42,90 & 71,64 \\
\hline
\end{tabular}

Médias seguidas pela mesma letra, nas colunas, não diferem entre si pelo teste Tukey a $5 \%$ de significância.

$\mathrm{Na}$ área II (Figura 5) o maior crescimento em altura, diâmetro e copa foram para as espécies amoreira-

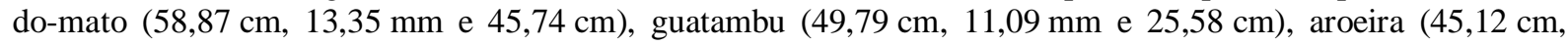
$6,75 \mathrm{~mm}$ e $19,13 \mathrm{~cm})$ e castanha-do-maranhão $(43,23 \mathrm{~cm}, 16,57 \mathrm{~mm}$ e $32,76 \mathrm{~cm})$. O jequitibá apresentou menor crescimento, com 35,26 cm de altura, 5,55 mm de diâmetro de caule e 29,61 cm de diâmetro de copa.
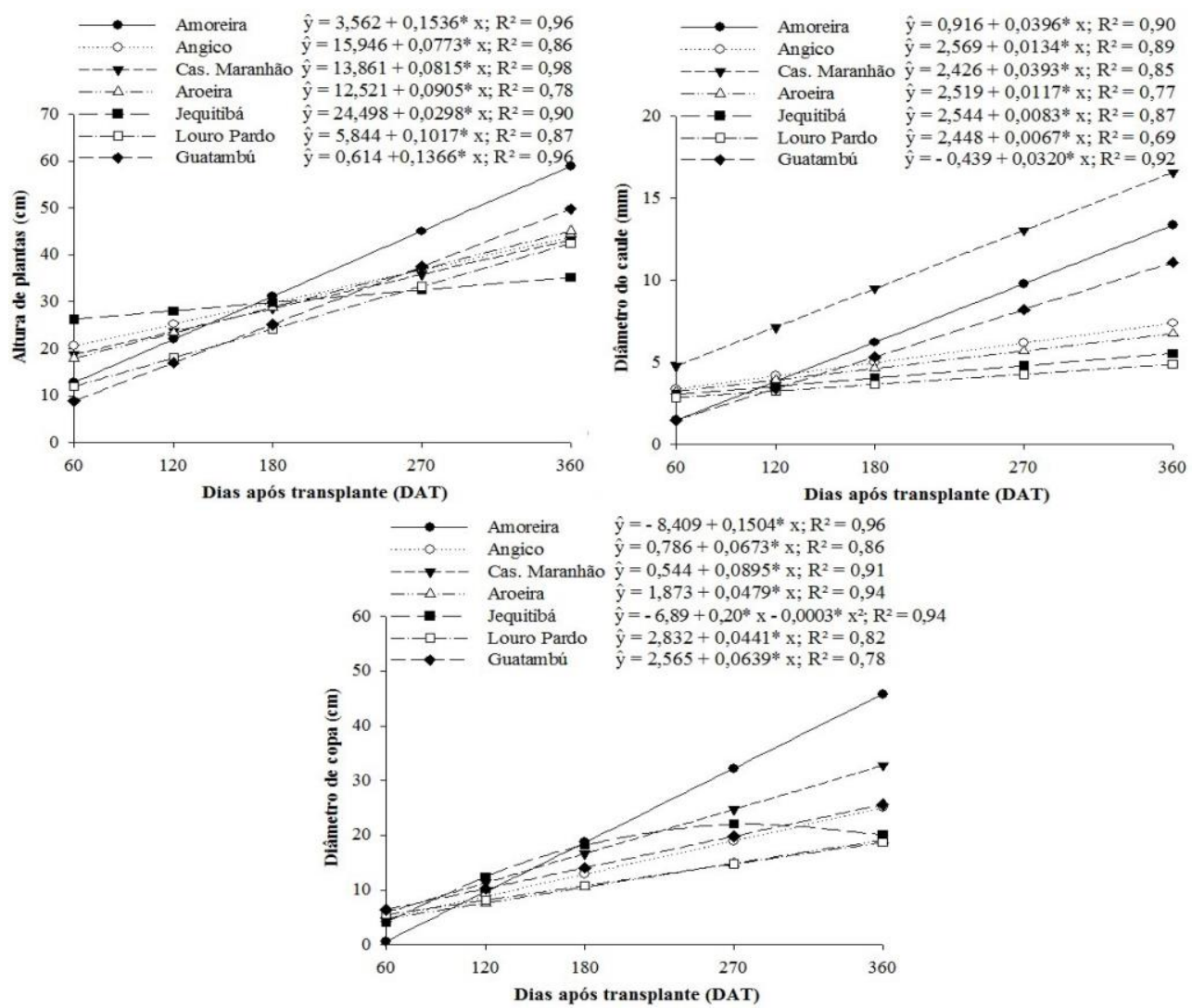

Figure 5. Altura, diâmetro do colo e projeção da copa das espécies inseridas na área II de acordo com as épocas de avaliação.

Figure 5. Height, stem diameter and canopy projection of the species included in the area II according to the evaluation periods.

As espécies que mais se destacaram na área III (Figura 6) foram a canafístula e o ingá, apresentando 118,76 e $85,32 \mathrm{~cm}$ de altura e 23,62 e 21,43 mm de diâmetro, respectivamente. 

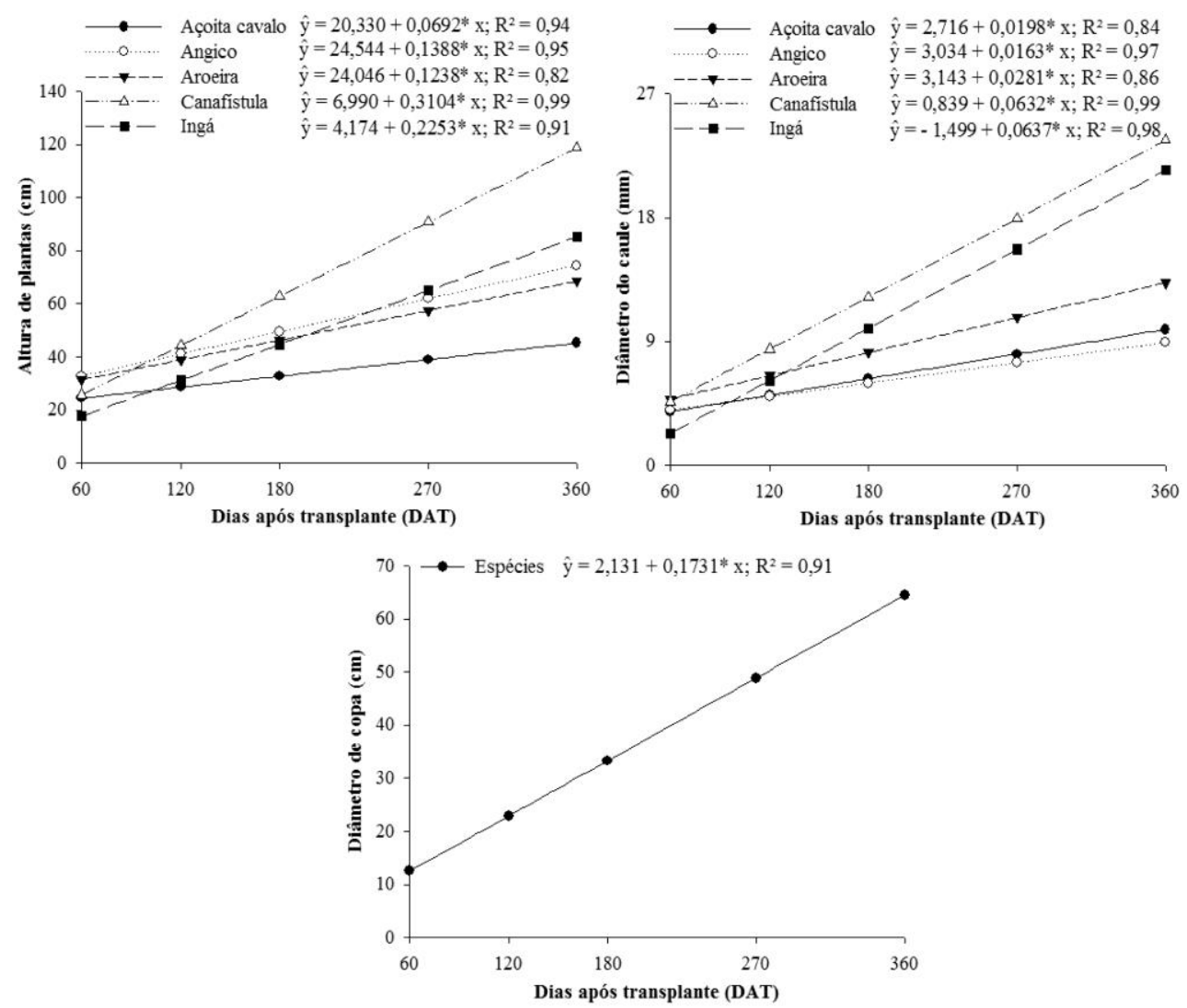

Figure 6. Altura, diâmetro do colo e projeção da copa das espécies inseridas na área III de acordo com as épocas de avaliação.

Figure 6. Height, stem diameter and canopy projection of the species included in the area III according to the evaluation periods.

Foi observada regeneração natural durante o período de estudo. O maior potencial de regeneração foi observado no grupo das pioneiras, refletindo, de modo geral, as características de sucessão natural. Encontraramse as seguintes espécies: Machaerium sp. Pers. (Fabaceae- Papilionoideae), Bauhinia forficata Link (FabaceaeCaesalpinioideae), Anadenanthera colubrina (Vell.) Brenan, Moquiniastrum polymorphum (Less.) G. Sancho (Área I); Nectandra lanceolataI Nees, Qualea megalocarpa Stafleu, Acrocomia aculeata (Jacq.) Lodd. ex Mart., Tabernaemontana hystrix Steud., Maytenus ilicifolia Mart. ex Reissek, Myrcia selloi (Spreng.) N. Silveira, Luehea paniculata Mart. \& Zucc., (Área II); Nectandra lanceolata, Bromelia karatas L., Machaerium sp., Maytenus ilicifolia, Anadenanthera colubrina, Moquiniastrum polymorphum, Vernonia sp Schreb. (Área III).

\section{DISCUSSÃO}

A sobrevivência de espécies plantadas em áreas degradadas depende de diversos fatores. As plantas estão sujeitas à competição por água, nutrientes e luminosidade com outras plantas, bem como à predação por animais. As condições edáficas do solo degradado provavelmente estão entre os fatores de maior impacto na sobrevivência das plantas. A menor sobrevivência das espécies na área III, indica, possivelmente, que o plantio de mudas em área de maior declividade do terreno deve ser diferenciado, e que a utilização de sacos não foi suficiente para proteger as plantas. Como nessa área o solo estava praticamente descoberto, os intemperes climáticos favoreceram a perda de solo, devido sua estrutura fraca.

Em estudo realizado por Ferreira et al. (2007), em que foi analisado o crescimento de espécies arbóreas plantadas em um gradiente topográfico verificou-se que, aos 155 meses após o plantio, a densidade de plantas foi menor na área de maior declive e as plantas remanescentes apresentaram menores valores de altura e diâmetro. Segundo os autores, o crescimento das espécies foi afetado pela presença de camadas restritivas ao crescimento radicular e pelo gradiente topográfico, possivelmente devido a maior perda de solo. Melotto et al. (2009) avaliaram o índice de sobrevivência e o crescimento inicial de espécies arbóreas nativas em pastagem de Brachiaria brizantha (Hochst. ex A.Rich.) Stapf, em Campo Grande, MS, e verificaram que as espécies 
Jacaranda cuspidifolia Mart., Tabebuia impetiginiosa (DC.) Standl. (atualmente Handroanthus impetiginosus (Mart. ex DC.) Mattos) e Myracrodruon urundeuva Allemão apresentaram os maiores índices de sobrevivência, respectivamente $100 \%, 100 \%$ e $93,75 \%$. Neste mesmo trabalho, as espécies $P$. dubium, A. colubrina e Cedrella fissilis Vell. apresentaram, respectivamente, 68,75; 56,25 e $25 \%$ de sobrevivência, avaliada aos 70 dias após o plantio.

A mortalidade de plantas também pode estar relacionada às condições climáticas adversas verificadas no período experimental (Figura 1), possivelmente desestabilizando estruturas e funções vitais do organismo. A fase inicial de estabelecimento das plantas em áreas degradadas se mostra a mais crítica (CAMARGO et al., 2002). Condições estressantes tais como períodos de seca prolongados aliados a altas temperaturas podem reduzir a abertura estomática de forma a limitar a perda d'água, porém, suprime a fotossíntese (RIZHSKY et al., 2004), e consequentemente, reduz as chances de sobrevivência.

Relacionando os dados de sobrevivência (Figura 3) e crescimento (Figuras 4-6), verificou-se que as espécies amoreira-do-mato, aroeira, cedro, canafístula e angico apresentaram potencial para recomposição da cobertura florestal da pastagem degradada, por apresentarem alta taxa de sobrevivência bem como forte incremento nas características de crescimento avaliadas. A. colubrina, $C$. odorata e $P$. dubium foram relatadas como boas espécies para recuperação de áreas degradadas (FERREIRA et al., 2007; MELOTTO et al., 2009). Estudos com espécies nativas enfocando as taxas de crescimento e de mortalidade além de um melhor entendimento das interações com outras espécies de plantas são de grande importância nas propostas de recolonização e restauração (FUENTES-RAMÍREZ, 2011).

Observa-se que na área I (Figura 4) as espécies de grupos iniciais de sucessão apresentaram maior porcentagem de sobrevivência, sendo três pioneiras (aroeira, amoreira-do-mato e canafístula) e três secundárias iniciais (amarelinho, cedro e jenipapo). Espécies de ambos os grupos sucessionais tendem a um comportamento semelhante, de crescimento mais acelerado. As pioneiras possuem maior flexibilidade de resposta frente às características ambientais de alta irradiância (BAZZAZ; PICKETT, 1980), ao passo que secundárias iniciais desenvolvem-se em clareiras pequenas ou, mais raramente, no sub-bosque, ocorrendo também em áreas de antigas clareiras, próximas às espécies pioneiras, caracterizando um grupo com certa plasticidade às condições de luz e sombreamento (SANTOS et al., 2004).

A falta de sombreamento rápido para o desenvolvimento das espécies secundárias tardias e climáxicas pode favorecer a morte de alguns indivíduos ou mesmo prejudicar seu desenvolvimento, no entanto a castanhado-maranhão (secundária tardia) e o jequitibá (climáxica) apresentaram bom desenvolvimento ao longo do período de avaliação. Camargo et al. (2002), observaram que mudas de espécies não pioneiras têm maior sobrevivência em ambientes mais perturbados, como áreas de pastagem ou solos descobertos, sendo atribuída à ausência ou redução de competição interespecífica e menores taxas de predação e herbivoria, apesar das condições microclimáticas extremas e das condições edáficas de baixa fertilidade e compactação.

Ferreira et al. (2007) demonstraram que espécies climáxicas têm ritmo de crescimento aumentado após 58 meses do plantio, enquanto as pioneiras têm seu ritmo diminuído nesse mesmo período. Tal fato justifica a maior proporção de pioneiras em relação às plantas não pioneiras utilizadas em projetos de reposição de cobertura vegetal.

Leguminosas arbóreas, segundo Cruz et al. (2011), merecem destaque quando o assunto é recuperação de pastagens degradadas, pois possuem sistema radicular profundo, propiciando melhor infiltração de água no solo e controle da erosão, melhorando também a fertilidade do solo. Faria et al. (1997), estudando o comportamento de nove espécies florestais, plantadas em área degradada, no Alto Rio Grande, Minas Gerais, em Latossolo Vermelho Escuro compactado, verificaram comportamento distinto entre as espécies e entre as adubações testadas. Dentre as espécies estudadas, $P$. dubium apresentou, aos 12 meses de idade, $1,24 \mathrm{~m}$ quando utilizada adubação química e orgânica associadas ( $100 \mathrm{~g}$ de superfosfato simples $+60 \mathrm{~g}$ de sulfato de magnésio $+5 \mathrm{~g}$ de sulfato de zinco $+3,0$ litros de esterco bovino) e 1,01 $\mathrm{m}$ quando utilizada somente adubação química (100 $\mathrm{g}$ de superfosfato simples $+60 \mathrm{~g}$ de sulfato de magnésio $+5 \mathrm{~g}$ de sulfato de zinco). Segundo os autores, nenhuma das espécies testadas teve desempenho satisfatório, devido principalmente às condições edáficas adversas.

A maioria das espécies regenerantes foram também espécies encontradas no fragmento de mata ciliar da APP no entorno da área de estudo. Resultado semelhante foi encontrado por Ferreira et al. (2010), sendo o fragmento o principal responsável pela regeneração natural em área degradada a jusante da hidrelétrica de Camargos, MG. O potencial de regeneração natural da vegetação de Cerrado é geralmente elevado, especialmente se comparado com ecossistemas florestais submetidos à impactos semelhantes. Todavia, a rapidez do processo de revegetação, a diversidade e a densidade da regeneração são determinadas pela intensidade e duração do impacto. 


\section{CONCLUSÕES}

- A declividade das áreas bem como a metodologia de plantio influenciou na sobrevivência das plantas durante os primeiros 360 dias após o plantio.

- As espécies amoreira, aroeira, cedro, canafístula e angico podem ser indicadas para restauração florestal por apresentarem alta taxa de sobrevivência e forte incremento nas características de crescimento avaliadas.

- O nível de degradação caracterizado pelas condições edáficas encontradas, implica em maiores esforços préplantio para redução da compactação e correções, no sentido de reduzir as taxas de mortalidade.

\section{AGRADECIMENTOS}

À Secretaria Municipal de Meio Ambiente de Jateí, principalmente ao Secretário Municipal Gerson Pereira Dias, pelo total apoio e concessão da área de estudo, bem como a utilização do Sítio Escola de Jateí para fornecimento das mudas. Ao Engenheiro Florestal Bernardino da Costa Bezerra (In Memoriam) por participar da execução e manutenção do experimento e principalmente ao conhecimento adquirido.

\section{REFERÊNCIAS}

BARbOSA, L. M. Manual Sobre Princípios da Recuperação Vegetal de Áreas Degradadas. São Paulo: Secretaria do Meio Ambiente, 2000.76 p.

BAZZAZ, F. A.; PICKETT, S. T. A. Physiological ecology of tropical succession: a comparative review. Annual review of ecology, evolution and systematics, Palo Alto, v. 11, n. 1, p. 287 - 310, 1980.

CAMARGO, J. L. C.; FERRAZ, I. D. K.; IMAKAWA, A. M. Rehabilitation of degraded areas of central Amazonia using direct sowing of forest tree seeds. Restoration Ecology, Washington, v. 10, p. 636 - 644, 2002.

CRUZ, C. A. F.; PAIVA, H. N.; CUNHA, A. C. M. C. M.; NEVES, J. C. L. Macronutrientes na produção de mudas de canafístula em Argissolo Vermelho Amarelo da região da Zona da Mata, MG. Ciência Florestal, Santa Maria, v. 21, n. 3, p. 445 - 457, 2011.

EHRENFELD, J. G.; TOTH, L. A. Restoration ecology and the ecosystem perspective. Restoration Ecology, Washington, v. 5, n. 4, p. 307 - 317, 1997.

FARIA, J. M. R.; DAVIDE, A. C.; BOTELHO, S. A. Comportamento de espécies florestais em área degradada, com duas adubações de plantio. Revista Cerne, Lavras, v. 3, n. 1, p. 25 - 44, 1997.

FERREIRA, W. C.; BOTELHO, S. A.; DAVIDE, A. C.; FARIA, J. M. R. Avaliação do Crescimento do estrato arbóreo de área degradada revegetada à margem do rio Grande, na usina hidrelétrica de Camargos, MG. Revista Árvore, Viçosa, v. 31, n. 1, p. 177 - 185, 2007.

FERREIRA, W. C.; BOTELHO, S. A.; DAVIDE, A. C.; FARIA, J. M. R.; FERREIRA, D. F. Regeneração natural como indicador de recuperação de área degradada à jusante da usina hidrelétrica de Camargos, MG. Revista Árvore, Viçosa, v. 34, n. 4, p. 651 - 660, 2010.

FUENTES-RAMÍREZ, A.; PAUCHARDB, A.; CAVIERESA, L. A.; GARCÍA, R. A. Survival and growth of Acacia dealbata vs. native trees across an invasion front in south-central Chile. Forest Ecology and Management, Amsterdan, v. 261, n. 6, p. 1003 - 1009, 2011.

GÜNTER, S.; GONZALEZ, P.; ÁLVAREZ, G.; AGUIRRE, N.; PALOMEQUE, X.; AUBRICH, F.; WEBER, M. Determinants for successful reforestation of abandoned pastures in the Andes: Soil conditions and vegetation cover. Forest Ecology and Management, Amsterdan, v. 258, n. 1, p. 81 - 91, 2009.

KAPLAN, E. L.; MEIER, P. Nonparametric estimation from incomplete observations. American Statistical Association Journal, Boston, v. 53, p. 457 - 481, 1958.

LORENZI, H. Árvores Brasileiras: Manual de Identificação e Cultivo de Plantas Arbóreas Nativas do Brasil. v. 1 e 2. Nova Odessa: Instituto Plantarum, 2002. 351 p.

MELOTTO, A.; NICODEMO, M. L.; BOCCHESE, R. A.; LAURA, V. A.; GONTIJO NETO, M. M.; SCHLEDER, D. D.; POTT, A.; SILVA, V. P. Sobrevivência e crescimento inicial em campo de espécies florestais nativas do Brasil central indicadas para sistemas silvipastoris. Revista Árvore, Viçosa, v. 33, n. 3, p. $425-432,2009$.

FLORESTA, Curitiba, PR, v. 46, n. 2, p. 277 - 286, abr. / jun. 2016.

Carnevali, N. H. de S. et al.

ISSN eletrônico 1982-4688

DOI: $10.5380 /$ rf.v46i2.42881 
RIBEIRO JÚNIOR, J. I.; MELO, A. L. P. Guia prático para utilização do SAEG. Viçosa: UFV, 2009. 287 p.

RIZHSKY, L.; LIANG, H.; SHUMAN, J.; SHULAEV, V.; DAVLETOVA, S.; MITTLER, R. When Defense Pathways Collide. The response of Arabidopsis to a combination of drought and heat stress. Plant Physiology, Rockville, v. 134, n. 4, p. 1683 - 1696, 2004.

RODRIGUES, E. R.; MONTEIRO, R.; CULLEN JUNIOR, L. Dinâmica inicial da composição florística de uma área restaurada na região do Pontal do Paranapanema, São Paulo, Brasil. Revista Árvore, Viçosa, v. 34, n. 5, p. $853-861,2010$.

SANTOS, J. H. S.; FERREIRA, R. L. C.; SILVA, J. A. A.; SOUZA, A. L.; SANTOS E. S.; MEUNIER, I. M. J. Distinção de grupos ecológicos de espécies florestais por meio de técnicas multivariadas. Revista Árvore, Viçosa, v. 28, n. 3, p. 387 - 396, 2004.

SHONO, K.; CADAWENG, E. A.; DURST, P. B. Application of assisted natural regeneration to restore degraded tropical forestlands. Restoration Ecology, Washington, v. 15, n. 4, p. 620 - 626, 2007.

SILVA, F. C.; ABREU, M. F.; PEREZ, D. V.; EIRA, P. A.; ABREU, C. A.; RAIJ, B. Van; GIANELlO, C.; COELHO, A. M.; QUAGGIO, J. A.; TEDESCO, M. J.; SILVA, C. A.; CANTARELLA, H.; BARRETO, W. O. Métodos de análises químicas para avaliação da fertilidade do solo. In: SILVA, F. C. (Ed.) Manual de análises químicas de solos, plantas e fertilizantes. 2. ed. Brasília: Embrapa Informação Tecnológica; Rio de Janeiro: Embrapa Solos, 2009. 627 p. 